\title{
4D MODELLING USING VIRTUAL COLLABORATIVE PLANNING
} AND SCHEDULING

SUBMITTED: April 2021

REVISED: September 2021

PUBLISHED: November 2021

GUEST EDITORS: Nashwan Dawood, Farzad Pour Rahimian

DOI: $10.36680 /$ j.itcon.2021.042

\author{
Mikael Viklund Tallgren, Research Engineer, \\ Department of Architecture and Civil Engineering, Chalmers University of Technology, Sweden; \\ mikael.tallgren@chalmers.se
}

Mattias Roupé, Associate Professor,

Department of Architecture and Civil Engineering, Chalmers University of Technology, Sweden; roupe@chalmers.se

Mikael Johansson, Researcher, Department of Architecture and Civil Engineering, Chalmers University of Technology, Sweden; jomi@chalmers.se

SUMMARY: During the last decades, the introduction of Building Information Models (BIM) has opened new possibilities to ensure better communication and a shared understanding between stakeholders in construction projects. Similar benefits have been found in 4D simulations of the schedule. While BIM and 4D use has seen a steady increase, the potential benefits have not fully been realised, primarily due to tools not supporting and enabling the full potential of collaborative stakeholder involvement in scheduling. The benefits of 4D simulations come from improving communication between stakeholders. While traditional 4D modelling connects an existing BIM model with an existing schedule, a move from this type of passive $4 D$ visualisation toward social co-creation enables all stakeholders to be involved in the scheduling process. This connection is further enhanced with the use of Virtual Reality (VR). Recent research has shown VR to enhance understanding and perception of the space and details and, thus, a better understanding of the project. This paper maps collaborative planning and scheduling method and traditional 4D scheduling using process modelling. This mapping is followed by implementing the 4D collaborative planning and scheduling method in the virtual project planning system with support for a multi-user interactive VR environment. The system enables social co-creation both during the planning and scheduling and during 4D modelling; it improves understanding of the project and the planning and scheduling.

KEYWORDS: 4D modelling, planning and scheduling, Collaborative work, Virtual Reality, Head-mounted displays

REFERENCE: Mikael Viklund Tallgren, Mattias Roupé, Mikael Johansson (2021). 4D modelling using virtual collaborative planning and scheduling. Journal of Information Technology in Construction (ITcon), Special issue: 'Construction 4.0: Established and Emerging Digital Technologies within the Construction Industry (ConVR 2020)', Vol. 26, pg. 763-782, DOI: 10.36680/j.itcon.2021.042

COPYRIGHT: (C) 2021 The author(s). This is an open access article distributed under the terms of the Creative Commons Attribution 4.0 International (https://creativecommons.org/licenses/by/4.0/), which permits unrestricted use, distribution, and reproduction in any medium, provided the original work is properly cited. 


\section{INTRODUCTION}

Schedules are vital and are used throughout all the phases of a construction project. The most common way to use and communicate these is by critical path schedules, Gantt charts and linked bar charts (Baldwin and Bordoli, 2014; Olivieri et al., 2019). Specialist planners or site managers most commonly create the schedule. Thus, the creation of the schedule is person dependant, and the schedule is based on general knowledge accumulated by the planner. However, it has been argued that site managers do not have enough time to spare to create quality schedules, and specialist planners lack the more specialised site knowledge to create realistic schedules (Winch and Kelsey, 2005).

Furthermore, research has shown that stakeholders' involvement in the scheduling process, such as subcontractors and the ones executing the work, removes the guesswork of planning and scheduling. Research also shows that involvement improves buy-in into the schedule at all levels (Dvir et al., 2003; Faniran et al., 1994; Viklund Tallgren et al., 2015). Schedules are communicational and managerial tools by nature, but visualisations such as Gantt diagrams and bar charts have been criticised, for example, for not conveying spatial relations (Chavada et al., 2012; Olivieri et al., 2019). It has also been argued that plans are often presented poorly with overly complicated information (Laufer and Tucker, 1987). Furthermore, schedules are hard to interpret for persons not trained in scheduling techniques (Chrzanowski and Johnston, 1986; Mahalingam et al., 2010). A way to address this has been seen in involving the different subcontractors in the planning and scheduling process, making it more collaborative. This involvement has been found to increase the understanding of the schedule and the project as a whole (Söderberg, 2006). The complexity of communicating scheduling information has also justified alternative approaches to visualise the schedule. One such method has emerged in the form of 4D CAD technology and 4D modelling (Heesom and Mahdjoubi, 2004), which has gained firmer ground with the adoption of Building Information Modelling (Boton et al., 2013). However, scheduling and modelling are often done in separate software and thus needs to be linked as a 4D model in another software. In this context, this paper explores and analyses how this traditional $4 \mathrm{D}$ modelling process can go from passive linking a schedule and a $3 \mathrm{D}$ model to a more active 4D modelling as part of the enhanced collaborative planning and scheduling process.

\subsection{Related work}

The literature shows that even though 4D offers potential advantages in, for example, the planners' communication of the schedule (Eastman et al., 2011: 6), it still lacks widespread adoption (Crowther and Ajayi, 2019). BüchmannSlorup (2010) argues that successful 4D implementation depends directly on subcontractors, suppliers, and manufacturers' involvement, which is not present at the moment. Due to this, the 4D simulation cannot be used to its full potential. Another limitation mentioned in the literature is that the currently available software offers little or no support for developing the 4D construction schedule. Consequently, this means that the user must put in more effort after creating the schedule to produce the $4 \mathrm{D}$ simulations through linking with the schedule (Campagna-Wilson and Boton, 2020; Tulke and Hanff, 2007).

Furthermore, the software and $4 \mathrm{D}$ processes assume that the schedule and the models are completed at a similar detail level. Campagna-Wilson \& Boton (2020) argues that the absence of processes, known methods, and instantiations for creating the 4D simulation in parallel with preparing the construction schedule is one of the significant limitations in the current implementation of 4D simulations. Additionally, literature also shows that BIM adoption has helped the construction industry move towards more collaborative approaches (Crowther and Ajayi, 2019). This move is supported in the research of Johansson et al. (2014), Viklund Tallgren (2018) and Viklund Tallgren et al. (2020) and has also opened for a more visual approach to communicating in the project. Formoso et al. (2002) argue that visual communication increases stakeholders' engagement and understanding of the project's problems. Roupé et al. (2019) report that Virtual Reality (VR) in the design phase allows stakeholders to understand the project better and move from passive interpreting to a more active co-designing role. Thus, the stakeholders' tacit knowledge can be worked into the project directly by the stakeholders. Further, VR lessens the risk for misinterpretation since there is less ambiguity in 3D than in customary design documents such as $2 \mathrm{D}$ drawings, where the user must internally visualise and interpret them (Roupé et al., 2019).

The increased use of BIM in the AEC industries and a new generation of affordable head-mounted displays (HMDs) have led to the industry gradually adopting more VR. With BIM, the required 3D data can be extracted directly from the model instead of creating it from scratch, making it more accessible in practice. Typical applications for VR today include construction safety planning and training (Azhar, 2017; Getuli et al., 2020; 
Hafsia et al., 2018) and site layout planning (Muhammad et al., 2020). In this context, many benefits have been shown. For example, tasks such as workspace planning are improved by drawing on experienced workers' knowledge and integrating it with construction managers' knowledge (Getuli et al., 2020). It also helps better share planning and safety-related information between project partners and its formal representation in a Health and Safety Plan. Goulding et al. (2014) also showed that VR could support the introduction and the learning of offsite construction production challenges and that it could mitigate "unforeseen problems often caused by professionals' decisions, faulty work, and health and safety issues". The use of HMDs also exemplifies how stakeholders could "step into" the model and experience the project in scale 1:1 and better understand the project (Roupé et al., 2019).

Moreover, in the case of design review sessions, previous studies have shown that VR can clarify many aspects of the design that is difficult to comprehend from traditional design documents, such as clashes and lack of space for installations and maintenance (Roupé et al., 2016; Zaker and Coloma, 2018). Also, it has been found that people with less experience in using desktop CAD/BIM viewers, for example, subcontractors and people who work in service and maintenance, prefers using VR to using desktop CAD/BIM viewers. This preference is traced to VR being seen to resemble better their natural work environment (Wolfartsberger, 2019). Recent studies demonstrate the use of VR, AR, BIM, Digital Twin, image processing and machine learning solutions to support automation in construction planning and monitoring activities on the construction site (Alizadehsalehi and Yitmen, 2021; Chou and Yang, 2017; Dadashi Haji et al., 2021; Lee et al., 2020; Pour Rahimian et al., 2019, 2020; Sheikhkhoshkar et al., 2019; Tiferes and Bisantz, 2018). As with BIM, VR is mainly seen during the design phase and almost not at all during actual construction. Approaches to a framework to incorporate constructability analysis using VR, BIM and 4D visualisations has been presented in Boton (2018).

However, the presented framework version has limitations such as:

- No possibility for users to do fully interactive, collaborative 4D definition sessions.

- $\quad$ VR is merely used to present predefined 4D simulations.

- Users cannot interact with the 4D model to add information such as annotations.

Boton (2018) argues that these aspects must be solved to make the experience of the VR-based 4D simulation more natural and relevant for the practitioners.

VR at the construction site have been studied in a series of research projects conducted between 2014 and 2021 , (Johansson, 2016; Johansson et al., 2014; Johansson and Roupé, 2019, 2021; Roupé et al., 2016, 2017). These studies aimed to use VR as a user-friendly interface to the BIM to help construction workers and site personnel explore, review, and understand the project and different work tasks better. Task such as extracting information, taking measurements and dimensions, and creating snapshots, production-oriented views for use during actual construction instead of predefined drawings.

During 14 different construction projects, the VR technology was evaluated with more than 100 different respondents from the construction sites. This research resulted in the VR software called BIMXplorer, which allows exceptionally large and complex BIMs to be visualised directly from source data, like an Industry Foundation Classes (IFC) file, without the need for any preparation or optimisation. From this comprehensive set of observations, interviews, and questionnaire responses, four things emerged when comparing VR to 2D-drawings or other non-immersive BIM tools;

- $\quad$ better user-friendliness,

- a better understanding and perception of space and details,

- a better understanding of different disciplines and the project as a whole,

- "Everyone sees the same thing with VR".

However, these studies also reveal many examples where construction workers quickly form an idea of issues. Examples of these can be seen in Fig. 1. The use of VR and "stepping in" and viewing the model on a scale of 1:1 has shown to ease the understanding and formulation of problems, such as clashes, design errors, or lack of space for a particular work task (Johansson and Roupé, 2019). Moreover, several examples have emerged where a VR review has led to changes in the sequencing of work tasks and changes to the actual design to improve production progress (Johansson and Roupé, 2021).

Thus, VR could bring an important additional dimension to understanding and reviewing the result during the planning and scheduling process. By integrating and supporting 4D in VR in the collaborative planning and 
scheduling method, creating a novel 4D modelling and collaborative planning process is possible. This process can change the traditional 4D process from a passive linking of the schedule and the 3D model to an active and interactive collaborative 4D modelling process that supports subcontractors' involvement and tacit knowledge from construction workers. In this context, subcontractors and construction workers could perform constructability analysis in 4D using VR.

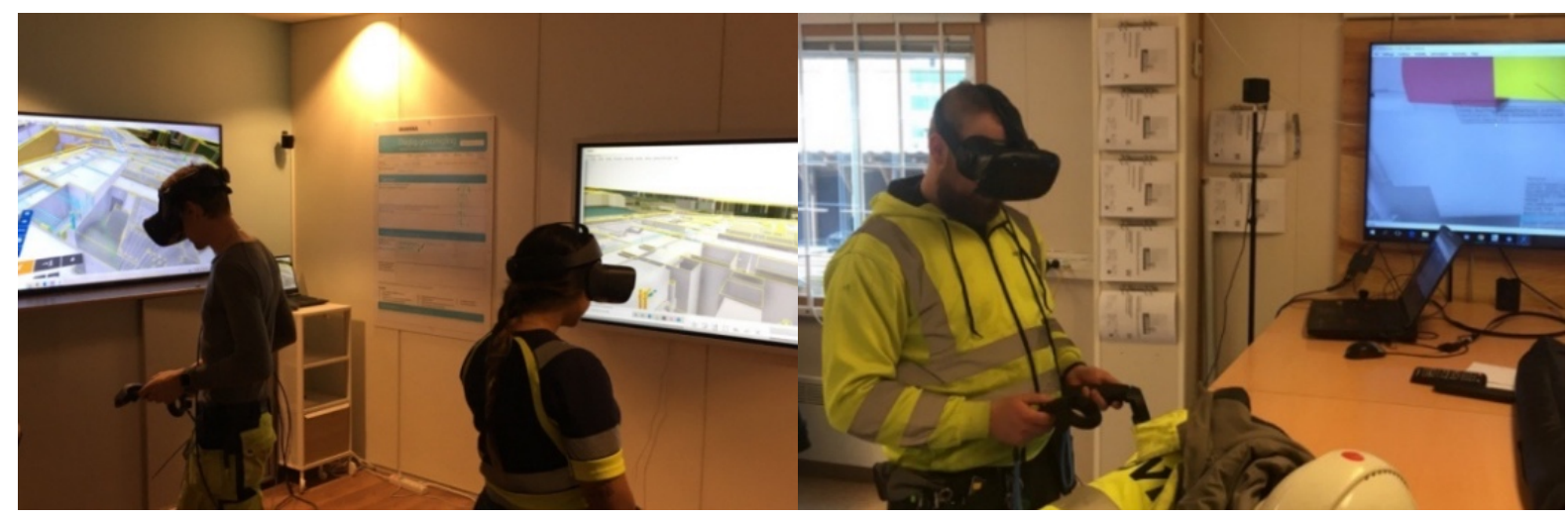

FIG. 1: Use of VR at the construction site (Johansson and Roupé, 2019, 2021).

Thus, these are the identified and addressed main issues:

- $\quad$ there are limited processes and known methods for the creation of 4D simulations in parallel with the preparation of the construction schedule,

- $\quad$ additional input is needed after the creation of the schedule to create and link the 4D simulations with the schedule,

- $\quad$ successful 4D implementation depends directly on the involvement of subcontractors, suppliers, and manufacturers, as the schedule is not based on specific data from construction site workers,

- $\quad$ planning and scheduling software are primarily aimed at expert planners; therefore, the software requires extensive knowledge and training to be effectively used, better user-friendliness is therefore needed,

- collaboration in planning and scheduling is limited, especially in the creation phase of the schedule,

- traditional Gantt and linked bar charts offer poor communication possibilities, especially with workers on-site. VR offers new communication possibilities.

This paper aims to analyse how the collaborative planning and scheduling approach presented within the article differs from the traditional 4D modelling approach. The original collaborative planning and scheduling process is instantiated and implemented in the Virtual Production Planning system (VPP-system) with VR. Thus, the paper contributes with:

- a comprehensive comparison between 4D modelling approaches,

- the outline of a user-friendly collaborative planning and scheduling tool that supports the involvement of subcontractors, suppliers and manufacturers, and specific data from construction workers,

- creation of a process that supports the integration of the construction schedule with 4D simulation simultaneously,

- a novel use of VR and HMD in the planning and scheduling phase in 4D to better communicate the project and the planning and scheduling problem,

- $\quad$ a set of cases exemplifying the improvements seen during evaluations.

\section{METHOD}

The research presented is a part of a larger research project, where design science (DS) has been used as the overarching research framework. The basis is a practice-based problem linked to the body of knowledge of the field and in-situ observations. DS as an approach is broadly defined as consisting of three activities, Design, Build and Evaluate, all of which are interrelated (Hevner et al., 2004; Hevner and Chatterjee, 2012: 1). This paper's data is compiled from prior observations, field notes, interviews, and evaluations performed in the overarching research project. For the collaborative planning and scheduling, in total, seven scheduling workshop observations with four 
different construction projects, seven interviews with nine workers and managers, and 15 prototype evaluations have been conducted (Roupé et al., 2014; Viklund Tallgren et al., 2015; Viklund Tallgren, 2018; Viklund Tallgren, Roupé and Johansson, 2020). Fig. 2. illustrates the multi-step research approach visually.

Study and analyse of the current planning process and set up requirements for developments:

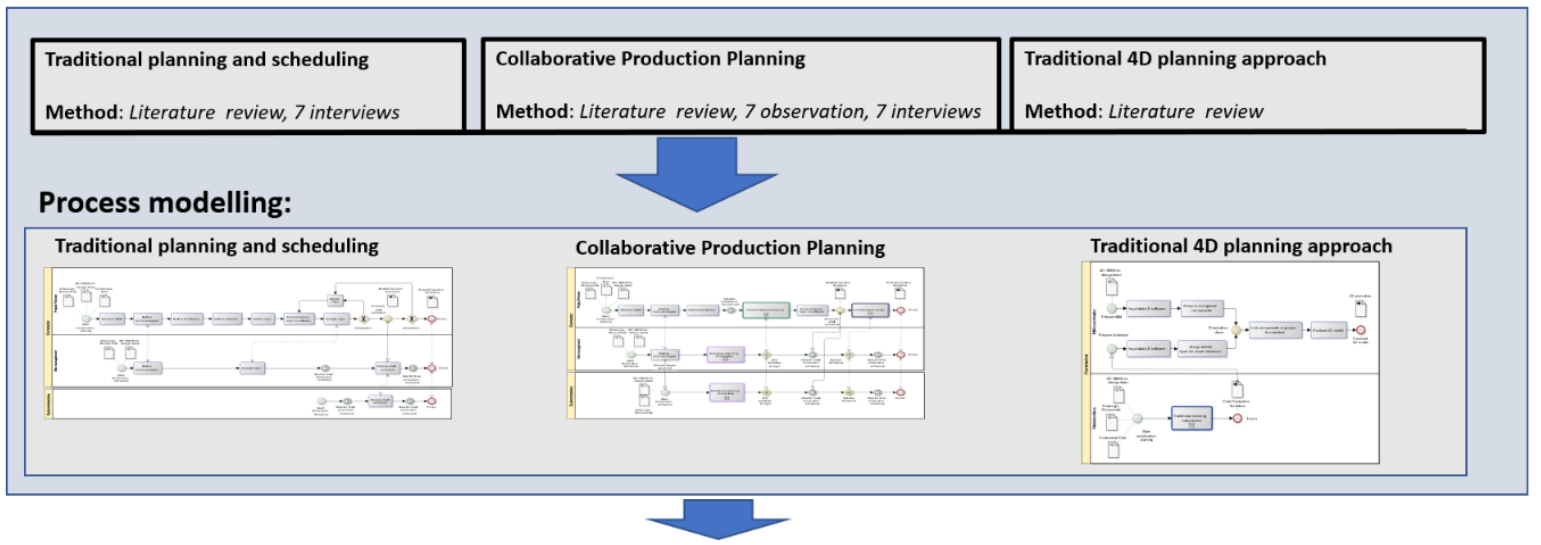

Design, development, evaluate: the Virtual Production Planning system:

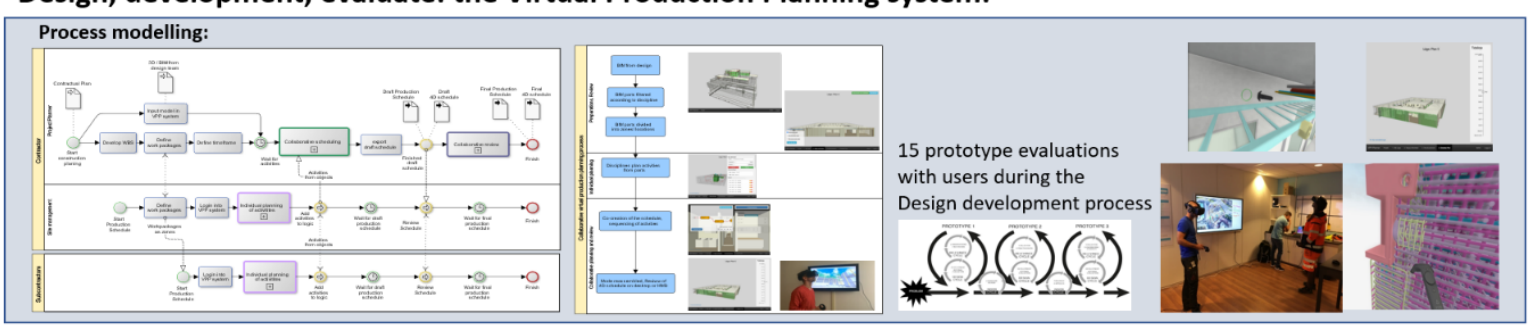

\section{FIG. 2: Illustrates and summarizes the multi-step research approach.}

The projects were selected due to their use of the collaborative planning approach described in Section 3 and their use of BIM. The seven projects were observed in their natural setting, with as little disturbance as possible. All seven workshops were followed as business as usual, and after the initial short presentation, the participants quickly went about the workshop at hand, largely ignoring the researcher. All but the first workshop was recorded with video and sound to ease the capture of interactions and communication. All workshops were documented with field notes that were thematically coded and analysed.

As a complement to the observations, seven interviews were held to understand the workers' need for information during construction planning and scheduling. All but one interview was conducted as semi-structured interviews, where an interview guide helped guide the interviews. This last interview was more of an unstructured interview in the form of a discussion. This interview aimed to capture the project planner's approach to planning and scheduling in general, especially regarding the original collaborative planning approach that he was pushing onto the projects for which he is responsible.

The 15 prototype evaluations focused on the usability and fit of the developed tool for the collaborative planning and scheduling process. Four of these evaluations were small informal evaluations with the closest research group to test functionality. Eight evaluations were to test the process and evaluate against best practice, conducted with middle managers, VDC-engineers, BIM coordinators and project planners from Scandinavia's five major construction companies and project management consultancy. Three evaluations validated the tool against the process and were conducted with construction management students, knowledgeable in the collaborative planning method. A more in-depth description of the primary data collection approach can be found in Viklund Tallgren (2018), where all but the last two observations and the four evaluations with BIM coordinators and project planners are covered since they have been conducted since 2018 . The collected data has been recorded and transcribed, then thematically coded with NVivo 12 . 
The analysis and modelling of processes have proved to be an effective way to compare and communicate processes and specify software system requirements (Aram et al., 2010; Ouyang et al., 2009). This paper uses the four-step approach described by Saluja (2009) to model the process:

1. Identify the set of activities that make up a particular task.

2. Identify the agent(s) involved.

3. Identify the intermediate and end goal for the task.

4. Identify what resources will be referred to or used for the completion of the task.

The traditional planning and scheduling process and the original collaborative planning approach in Scandinavia presented in Viklund Tallgren, Roupé and Johansson (2020), have been modelled with these four steps using the original Business Process Modelling Notation (BPMN) notation rather than the layout presented in Saluja (2009), to communicate the responsibilities of distinct roles better. Furthermore, as a basis for modelling the different planning and scheduling approaches and the conventional 4D modelling approach and the collaborative 4D modelling approach, a literature review, observations, and an interview with a project planner have been used. Process modelling, especially the BPMN, is proven and used amongst stakeholders in the buildingSMART Alliance to supply a transparent and reproducible way to communicate process flows (Borrmann et al., 2018: 4).

\section{PLANNING AND SCHEDULING PROCESSES AND VISUALISATIONS}

Planning and scheduling processes can be described in several ways. This paper uses the seven-step planning process described by the project management institute (Jones, 2009). According to findings in literature and interviews, the general planning process is further extended with the workflow for site management and subcontractors (Baldwin and Bordoli, 2014; Christiansen, 2012; Friblick and Nordlund, 2013). As seen in Fig. 3, the traditional pre-construction planning and scheduling have three main stakeholder groups, the project planner, site management and sub-contractors.

The project planner is an active stakeholder, while site management and sub-contractors are passive concerning planning and scheduling. The project planner performs both the work breakdown structure (WBS) and the definition of work packages that break the WBS into distinct units or phases. Each work package is then planned by defining activities or tasks needed to complete a work package. When activities are defined, the hard logic of the schedule is decided. Hard logic is how activities depend on and follow each other. The planner inputs the schedule into a planning software such as Primavera, Powerproject, MS project or Synchro, and once this is done, the logic is analysed, and errors corrected. The result is a draft schedule that is circulated to stakeholders. The draft schedule is reviewed with the stakeholders, working in the feedback into the schedule before finalising. As seen in Fig. 3, the site manager has some input into the scheduling, but the subcontractors are primarily passive recipients of the schedule.

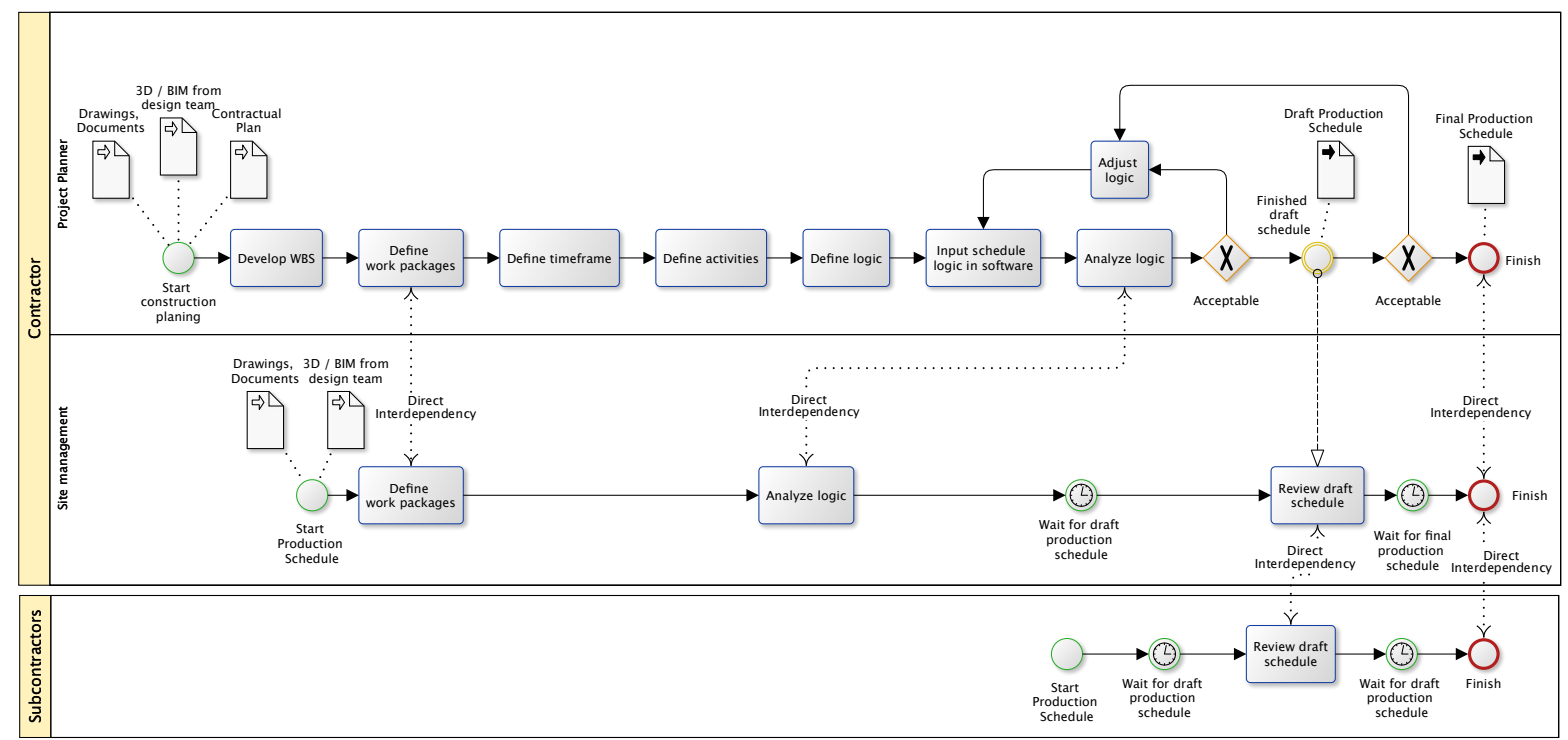

FIG. 3: The traditional planning process. 
In Viklund Tallgren (2018), an interview with a project planner showed that this was often a problem since it meant the planner would have to push and "sell in" the schedule to gain acceptance for it, and even then, the subcontractors saw it merely as a loose guideline. Furthermore, the literature also argues that more training is needed to enable site management to engage more in planning scheduling and make it more collaborative to lighten the project manager's planning load (Crowther and Ajayi, 2019).

\subsection{Traditional 4D planning}

The traditional 4D planning approach is documented in the literature, with two main methods identified. One is manual stitching of pictures of a 3D model chronologically, representing stages in the production process, resulting in a movie that can be played back (Baldwin and Bordoli, 2014: 9; Eastman et al., 2011). Manual stitching was typical before the introduction of BIM and is the most passive 4D approach. The other method is a more interactive one where the schedule and the BIM model is linked (Baldwin and Bordoli, 2014: 9; Crowther and Ajayi, 2019). The most common way to achieve the linking approach to 4D visualisation is to conduct the traditional planning and scheduling process as usual, as indicated in Fig. 4 in the lower swim lane, as a subprocess for stakeholders such as the project planner as described in the traditional planning and scheduling process in Fig 3.

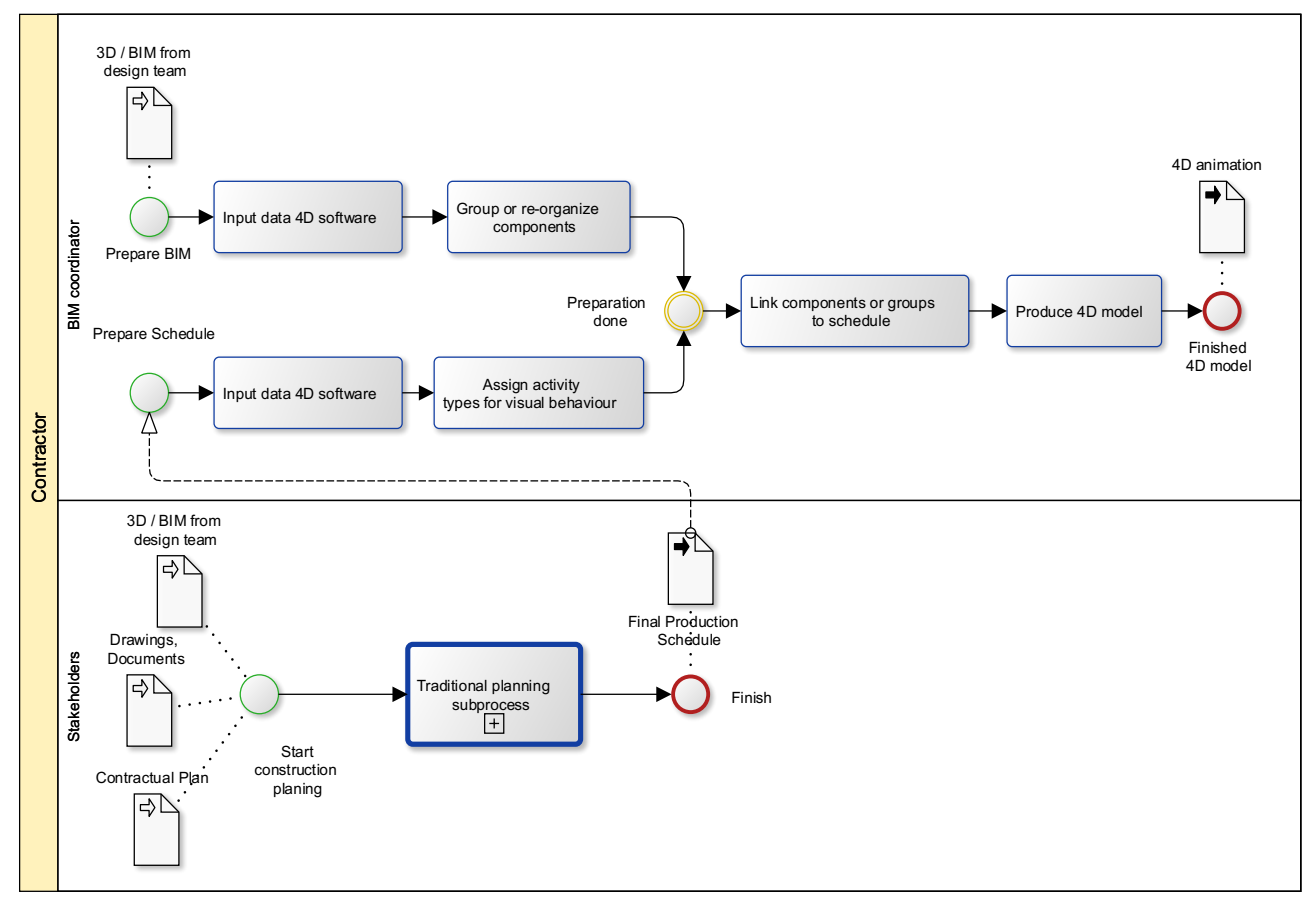

FIG. 4: Traditional 4D modelling process.

The complete schedule is then given to a BIM specialist like a BIM coordinator, who merges the schedule and the models. As seen in the upper swim lane in Fig. 4, this linking is prepended with two separate preparatory paths. One path is the input of the 3D data and/or BIM model into the 4D software and the re-organisation and grouping of components according to the construction strategy. The other is preparing the construction schedule by importing it and setting up activity types for visual behaviour to visualise the construction process. This preparation could be done by coding the objects or utilising the grouping of objects.

Similarly, in the lower path, the schedule is imported, then the visual behaviour is defined. These behaviours are usually different colouring or transparency of objects to indicate existing-, being-built-, finished-, temporary- or demolished- phases. After the preparations, the BIM coordinator works through the activities, linking components from the model to the schedule. Once all modelled parts are connected and other temporary activities added, the $4 \mathrm{D}$ visualisation can be produced. The $4 \mathrm{D}$ visualisation is done either as a movie or as an interactive visualisation model. As seen here, specialist competence is needed to create 4D visualisations. One reason for this is the need for a good understanding of the information structure in the 3D / BIM model and knowledge of the 4D systems, which are often more advanced than standard scheduling software. 


\subsection{The collaborative production planning}

The original collaborative planning process described here is defined in Viklund Tallgren (2018), and further elaborated in Viklund Tallgren et al. (2020), and builds upon the collaborative planning and scheduling approach developed during the late eighties and early nineties (Friblick and Nordlund, 2013; Söderberg, 2006), and was called Integrated Planning (IP). In Scandinavia, these approaches were driven by the workers union, with a strong belief in codetermination in workshops and flatter hierarchies, leading to workers or supervisors from the different subcontractors taking part in the planning and scheduling process (Söderberg, 2006). However, what was recognized during the seven initial workshops, was that original IP method and process had been developed to fit a more specific collaborative production planning process (Viklund Tallgren, Roupé and Johansson, 2020). In this paper, we distinguish this by calling current method, Collaborative Production Planning (CPP). This approach has similarities to the Last planner concept from the Lean construction field. Still, it is not as strict in using pull planning vs push planning and specific schedule visualisation techniques (Friblick and Nordlund, 2013).

The main difference from traditional planning and scheduling is that the planner does not actively plan; thus, the planner does not define activities or the schedule's hard logic. Instead, the planner acts as a moderator during the workshop while sequencing the activities. Fig. 5 shows the basic layout of the CPP process.

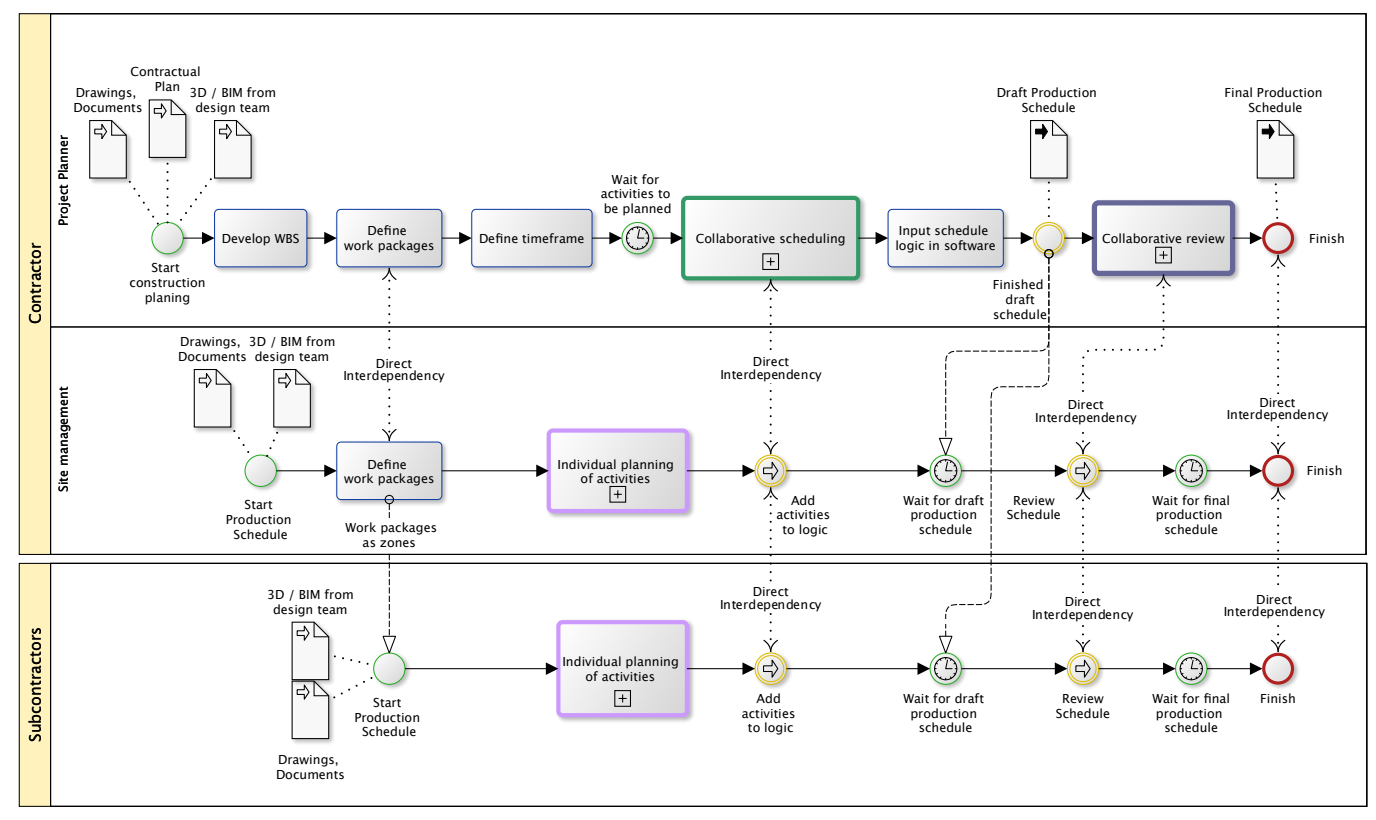

FIG. 5: General Collaborative Production Planning (CPP) process.

The main difference compared with the traditional planning process in Fig. 3 is that the project planner works closely with the site management in defining work packages. These work packages are then used during the CPP workshop to limit the scope of the scheduling. One work package is planned and scheduled at a time. This process is illustrated by an individual planning process, shown in Fig. 6.

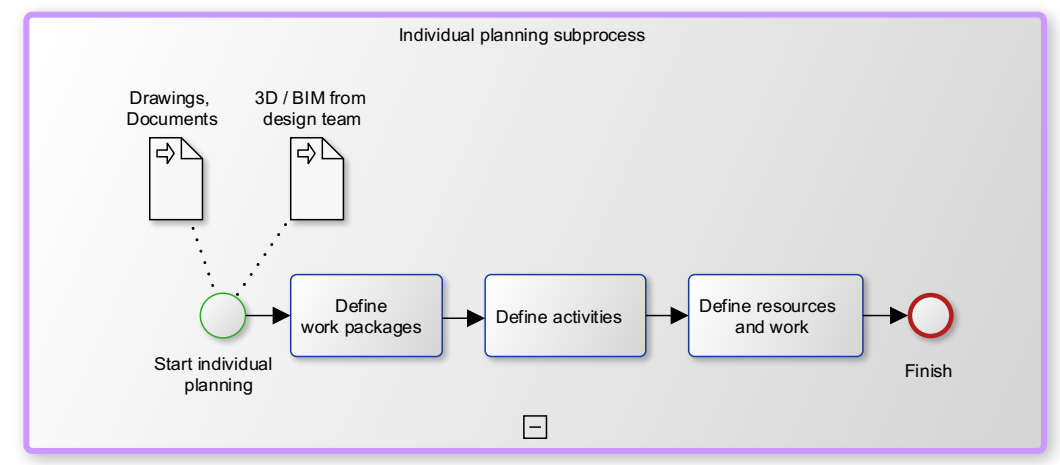

FIG. 6: Individual planning subprocess in the CPP process. 
This move of responsibilities is the main difference compared to the traditional planning process. Supervisors from the site management and subcontractors are responsible for planning their specific activities, thus moving the planning and scheduling from the expert planner to the ones performing the work. These workshop observations show that much of this activity definition is done during the scheduling workshop while actively communicating with closely related disciplines, thus minimising the risk of misinterpreting other disciplines' work. Activities are created on sticky notes, one activity per sticky note, with name, resources, duration, and location specified. This process is similar for subcontractors and site management, who plans the general work not related to subcontractors to be conducted in each work package. Once all activities in a work package are defined, the sequencing of the schedule starts. The sequencing part of the workshop is the switch from independent individual planning to collaborative scheduling work. The collaborative scheduling subprocess is modelled in Fig. 7. The observations show that the project planner takes more of a monitoring and managing role in seeing that all stakeholders share knowledge and define the best possible sequence for the work package at hand. All stakeholders are responsible for their activities and add their sticky notes to the schedule, represented by big sheets. Thus, the current work package forms an agreed-upon sequence. This sequencing goes on until all activities are sequenced and all hard logic defined.

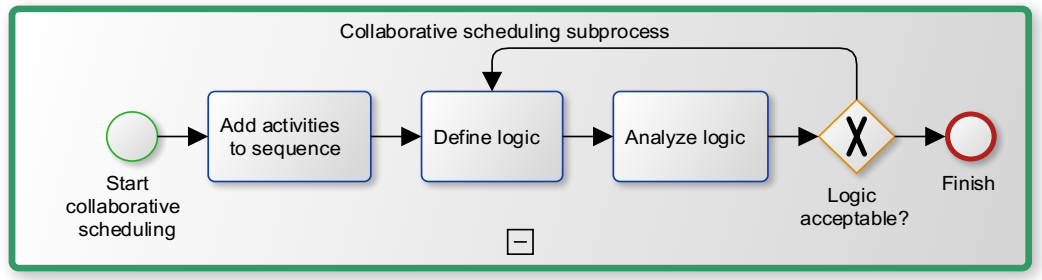

FIG. 7: Collaborative scheduling subprocess in the CPP process.

Observations conducted during CPP workshops shows that some constructability issues can be found and feedback to the design team, thus rectifying issues before they start the construction (Viklund Tallgren et al., 2020). Once this is done, the project planner and the stakeholders review and analyses the schedule to identify potential problems or errors; this is shown in more detail in the collaborative review subprocess in Fig. 8.

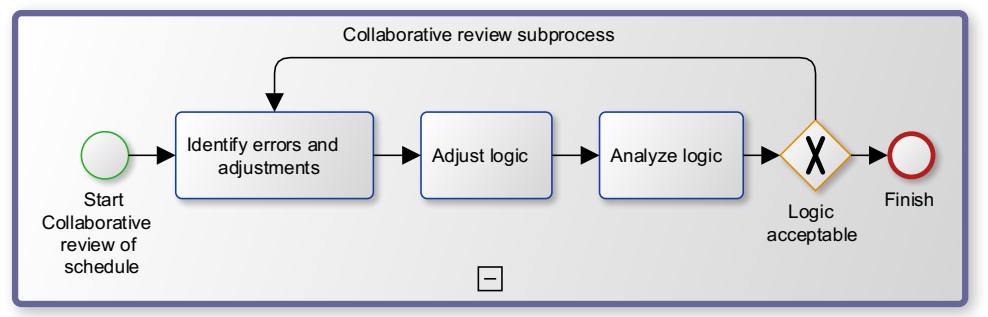

FIG. 8: Collaborative review subprocess in the CPP process.

Here the observations showed that some rework of the logic was done, and information on activities was supplemented, and sometimes even new activities added. This addition usually meant substantial rework of the logic. Thus, as a first draft, a pencil was used to draw connections, the hard logic. Once the schedule logic was finalised, the logic was permanented with markers. During discussions with project planners from several Scandinavian construction companies, some mentioned that they used whiteboards instead of paper to record the logic, then photographing the finalised logic (Viklund Tallgren, 2018; Viklund Tallgren, Roupé and Johansson, 2020). Once all the work packages are worked through similarly, the project planner takes the sheets of papers and records them in the scheduling software. Observations and interviews have shown that the number of projects the project planner is responsible for affects the time taken to finalising the work, taking up to a couple of weeks. The planner mentioned that scheduling logic errors are common in the physical plan (Viklund Tallgren, 2018; Viklund Tallgren, Roupé and Johansson, 2020). These errors are often found during input in the software, which leads to the planner making assumptions to solve these errors. The resulting schedule is typically an idealised schedule that needs to be optimised to adhere to the contractual plan. The un-optimised draft schedule creates the need for a follow-up workshop. The draft schedule is collectively reviewed during the follow-up workshop, and hard logic is suitably adjusted until the schedule's timeframe coincides with the contractual plan. In an interview with the planner, it was mentioned that the philosophy behind this approach is to let the group initially be free from time constraints and thus being able to focus on hard logic such as the suitable sequences and relations between activities 
logic (Viklund Tallgren, 2018). Therefore, optimisation should be done in a second step once the logic is in place. The project planner reworks the schedule, and the logic is adjusted and agreed upon before, the process is repeated until a final schedule is produced and sent out to all stakeholders. When considering the CPP method, several timewastes can be identified, such as waiting for the schedule and the connection of activities to a schedule, and these show potential for enhancement with digitalisation, for example, through BIM.

\section{THE IMPLEMENTATION IN THE VIRTUAL PRODUCTION PLANNING SYSTEM}

The virtual production planning system (VPP-system) instantiates and implements the collaborative production planning (CPP) method described in Fig. 9 in an artefact, the VPP-system. It partly provides a BIM-based web interface for each stakeholder to plan and schedule their activities, and partly an HMD interface through BIMXplorer to experience the project. VR enables the users an immersive review of the project and the schedule. Fig.9 illustrates the interfaces connected to the VPP-system, where the BIM model is used as the information carrier, and a database is used as the hub connecting different clients.

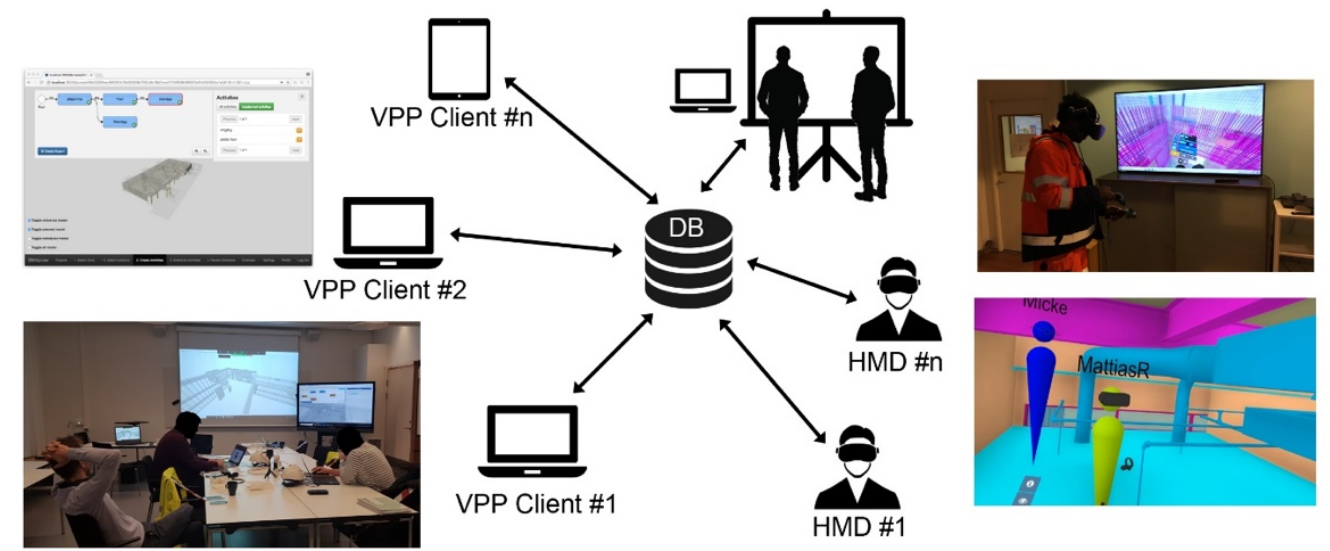

FIG. 9: An overview of the implementation of the collaborative planning and scheduling method in the VPPsystem connected to multi-user VR used for $4 D$-simulation.

The VPP-system and the Application Program Interface, API, connecting the clients and the database is described in more detail in Viklund Tallgren (2018). The goal has been to keep the process as close as possible to the original CPP process while still having a user-friendly interface. Thus, keeping the process but changing the implementation. BIMXplorer is used to visualise the entire model to offset the web interface's memory limitations handling big, detailed models (Johansson, 2016). As the VPP-system is web-based and communicates through API with a server, the different users could collaborate both co-located and remotely. The VPP-system and CPP method supports integrating the preparing of the construction schedule with the 4D simulation simultaneously, see Fig. 10 and 11. The VR based 4D-simulation also supports multi-user collaboration and avatars in VR and support remote conversations and dialogues through the microphone and headphones on the HMD, see right part of Fig. 9. The user interface of the clients has been developed during iterative evaluations in collaboration with the construction industry.

The primary planning and scheduling process is modelled on the CPP process in Fig. 5. However, all stakeholders interact with the BIM model to create activities rather than physical sticky notes, resulting in the process seen in the middle swim lane of Fig. 10. Since the VPP-system is web-based, it requires the BIM model to be uploaded to the system. Preferably somebody with the project responsibility does this, such as the project planner, project manager or a BIM coordinator. Also, as in the traditional 4D modelling process in Fig. 4, there is a need to define the WBS and work packages in locations. According to many projects' delivery manual, this process is done in the design phase through coding and classification. Thus, the classification and coding resemble the grouping of parts done in the preparation stages of the traditional 4D modelling process. The classification and coding system used in the model helps to filer the model disciplines according to subcontractors. Once the model is in the VPPsystem, the collaborative planning and scheduling workshop can take place. Each discipline creates its activities by selecting components of the BIM model. These components make up an activity, and the user put in the name, resources, and duration of the activity. See the middle swim lane of Fig. 10, marked individual planning for an 
example. These digital activities replace the sticky note and enable the user to get information directly from the objects that are part of the activity. Thus, the activity is connected to the model already in the creation phase of the activities.

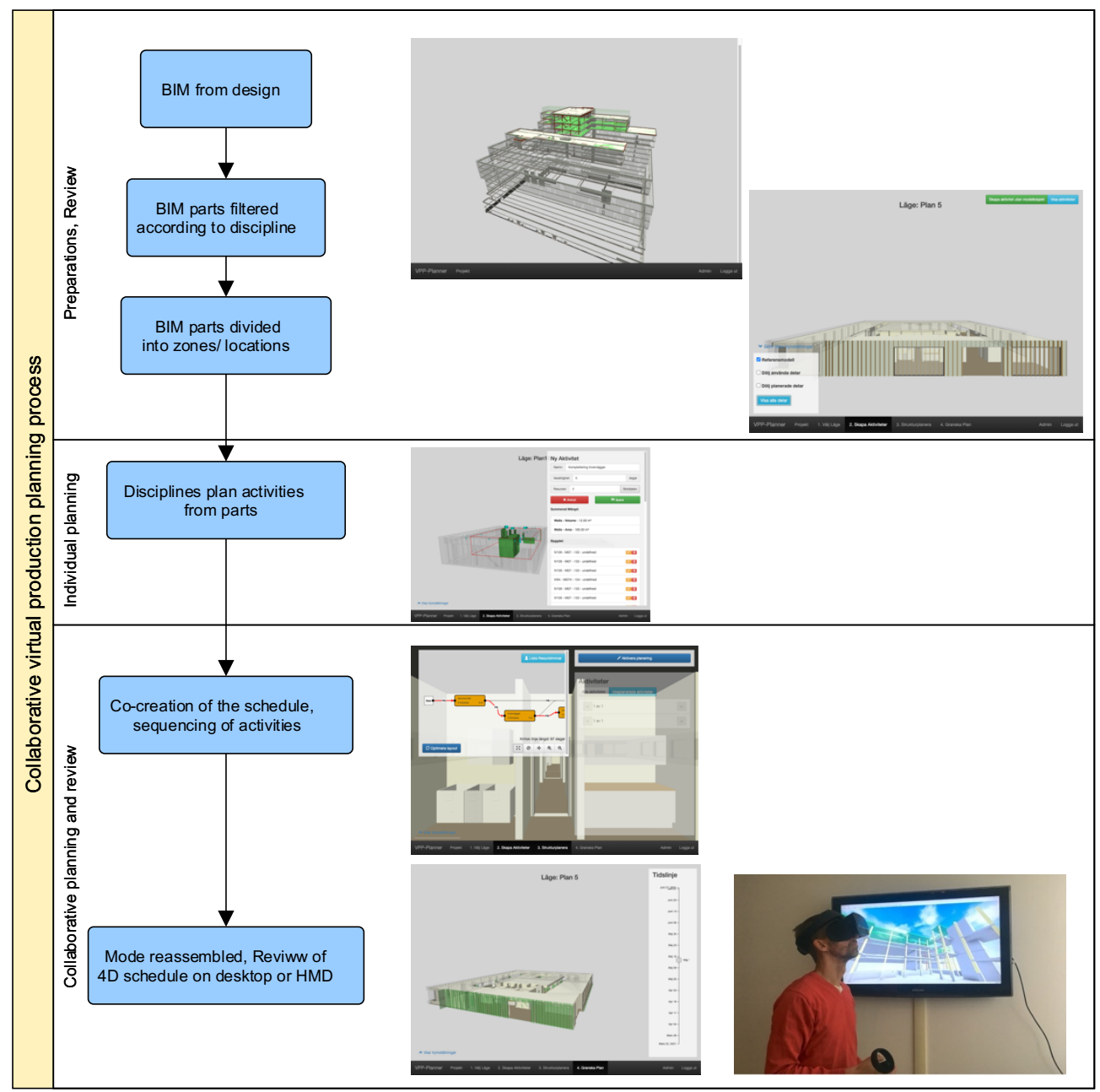

FIG. 10: The Virtual Production Planning system (VPP-system) and collaborative production planning and scheduling method supporting 4D approach.

The sequencing of the logic is done collaboratively similarly as described earlier in Fig. 7 and Fig. 8. However, instead of physical sticky notes, each stakeholder drags and drops the activity to schedule and connects it with the needed logic. See the lower part of Fig. 10, the collaborative scheduling and review. In the background, the VPPsystem calculates the critical path and work package duration based on the duration of the logic and critical activities and sends updates to the other clients and the BIMXplorer HMD interface, see section 4.1 and Fig. 12 for details. The result is an instantly reviewable schedule. Evaluations of the VPP-system with participants experienced in the sticky-note version of the CPP method mentioned that the VPP-system was more natural to grasp (Viklund Tallgren, Roupé and Johansson, 2020). Mainly because the schedule overview was better, and the schedule's adjustment compared to the physical sticky notes and arrows on big sheets on paper was more effortless. The ease of rearranging and changing connections between activities were especially appreciated by the evaluators.

A difference with the VPP-system compared to the traditional 4D modelling process is that in the VPP-system, the 4D model is created continuously as the project is planned and scheduled. A 4D visualisation becomes an added result along with the schedule once the sequencing is done. See the bottom of Fig. 10 for the collaborative scheduling view and 4D review view, both in the VPP-client and in an HMD. Hard logic can be reviewed continuously if uncertainties of the best sequence should arise. The ability to instantly check the schedule reduces the lead time between the workshop and the completed schedule. The project planner can bring up and make the 
final edits in the workshop before concluding the workshop, thus shortening the time gap between the workshop and the finished and agreed upon production schedule. The resulting schedule can be extracted and put into scheduling software. Fig. 11 illustrates the artefact's implementation in the VPP system, where Individual planning, Collaborative scheduling, and Collaborative review subprocesses are supported. See Fig. 6-8 for details on these subprocesses.

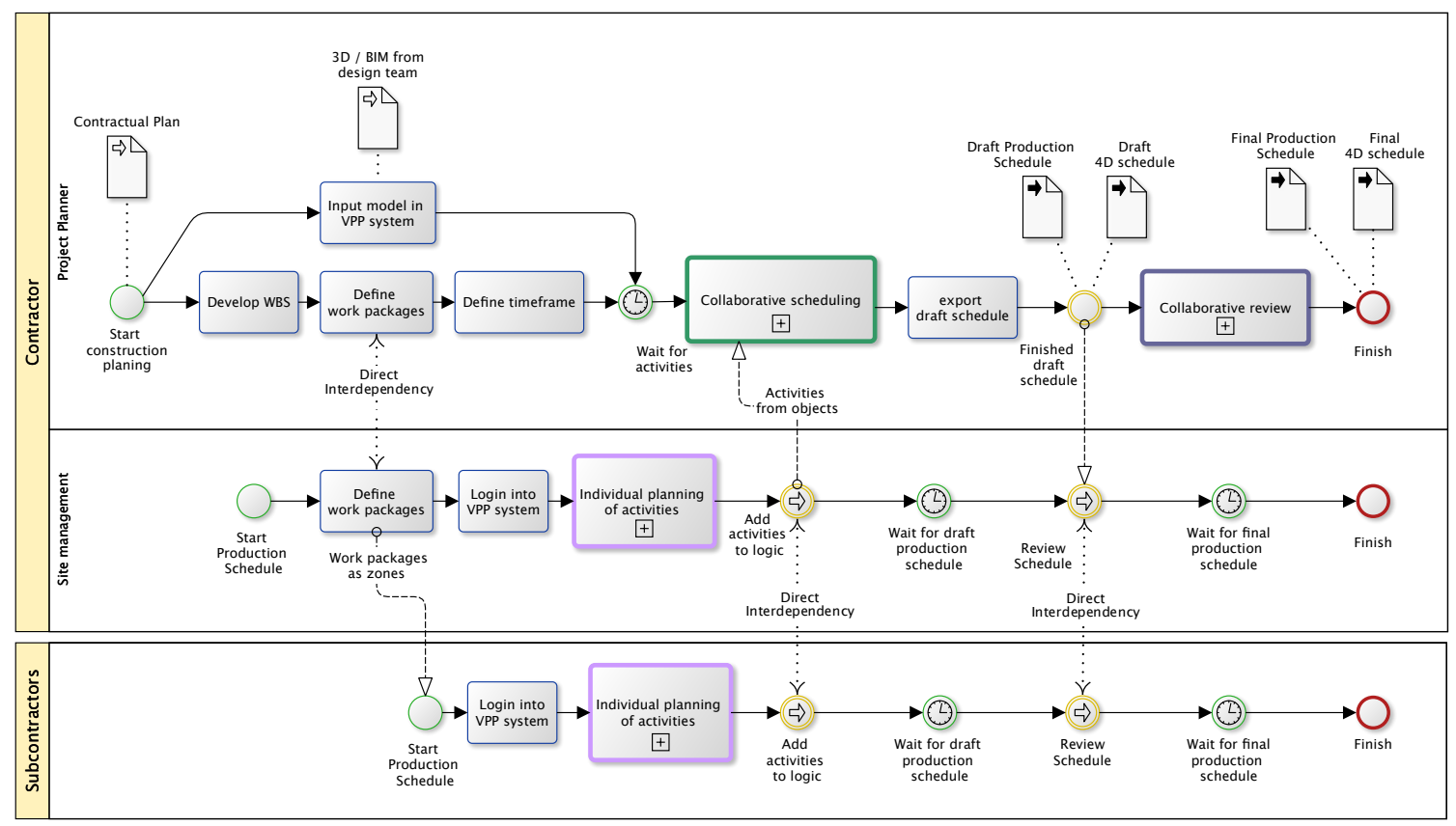

FIG. 11: The implemented VPP system, for details of Individual planning subprocess, see Fig. 6 Collaborative scheduling subprocess see Fig. 7, and for Collaborative review subprocess see Fig. 8.

\subsection{Extension into immersive VR}

Since the VPP-system was designed with a web interface that uses an API to communicate with the server, it enables connecting and extending it to other interfaces as well. The connection between tools is facilitated by a WebSocket communication protocol, which means that the VPP-system can connect to one or several BIMXplorer clients. Workshop participants can utilise BIMXplorer to review the 4D schedule on a scale of 1:1 in an HMD, as seen in Fig. 12.

The 4D capabilities in VR are used by setting the visible state of objects according to the schedule. The states are represented by colouring and transparency, indicating existing-, being-built- finished phases. These states can be seen in Fig. 13, where the model's top floor is coloured to indicate being built while the rest of the objects are finished. The VR client uses the same BIM as used in the VPP-system and then registers for notifications from the VPP-server. With each object in the BIM having a Globally Unique Identifier (GUID), the VPP-server only needs to send the GUID together with a boolean indicating visible/invisible state to update the VR-model according to the schedule.

The change of the 4D time-slider initiates a broadcast of a list with the affected GUIDs to any connected clients. The clients use the list to update the visible state of the corresponding objects in the client. When in VR, participants can freely navigate around in the BIM in scale 1:1 and take distance measurements and query objects for properties in the same way as previously described in Johansson \& Roupé (2019), see Fig. 14. The VR interface supports the user/participants in the VPP-process to understand in more detail measurements needed and what product they should construct, install, and schedule. The annotation, distance measurements and information are also supported in remote multi-user collaboration during the 4D simulation. An example from the VR environment can be seen in Fig 14 . 


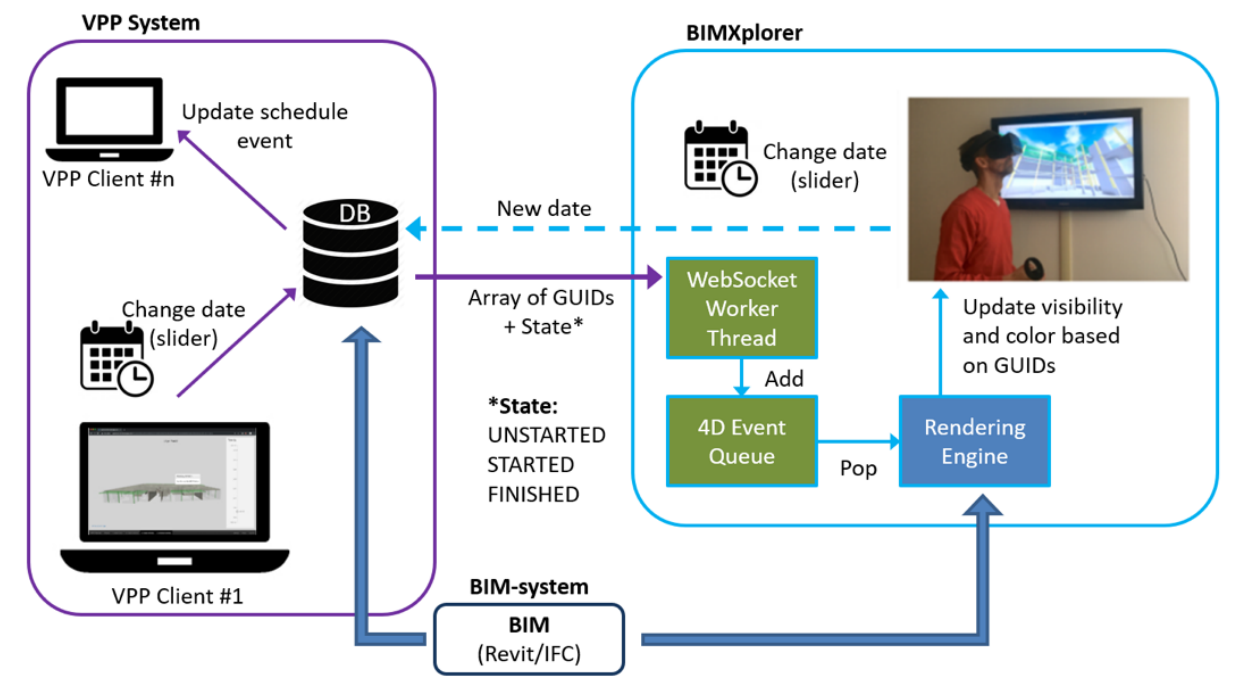

FIG. 12: An overview of the main exchanges and communication between the different applications, which support the VPP collaborative planning and scheduling method and $4 D$ simulation in VR.
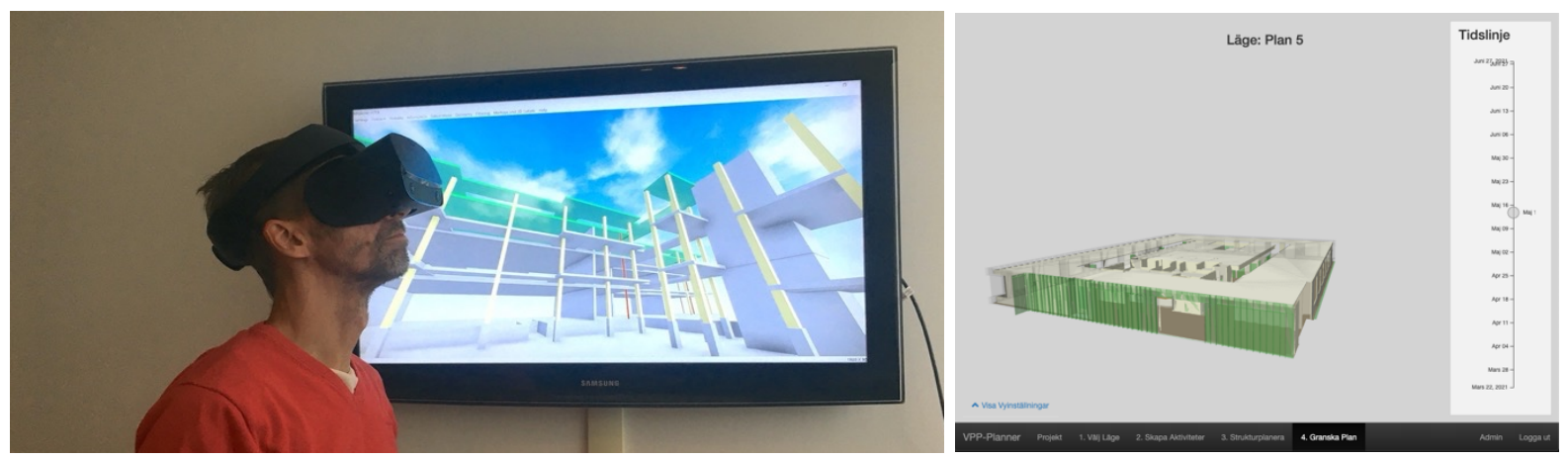

FIG. 13: A user reviewing the $4 D$ visualisation in an HMD and a VPP-client showing the schedule review view.

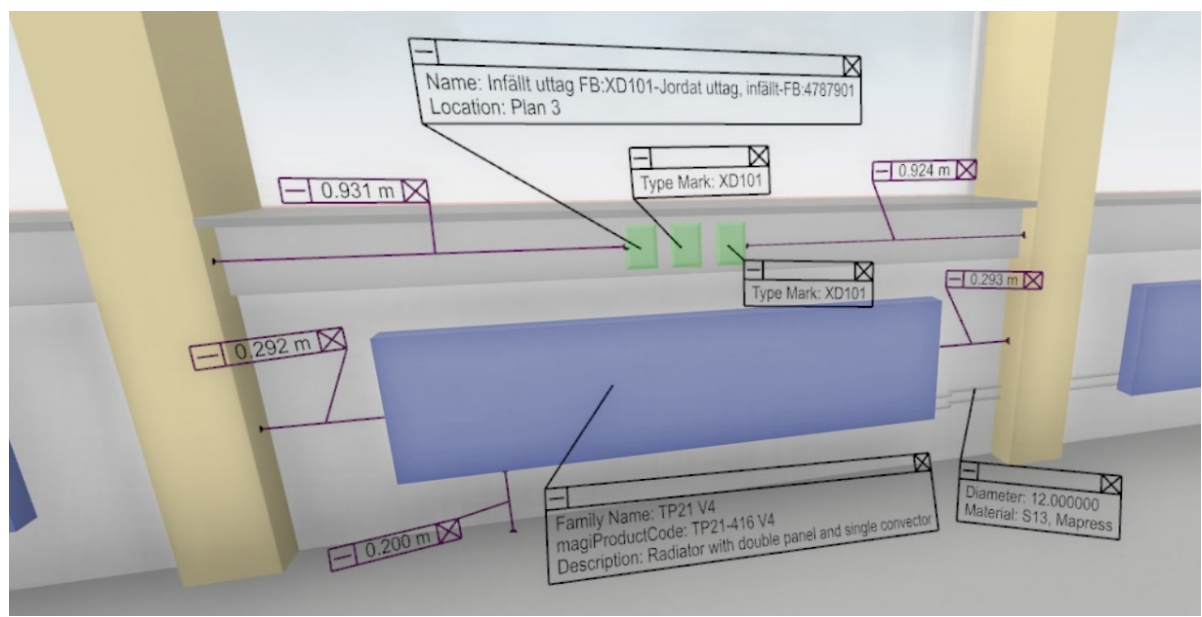

FIG. 14: In VR the user can freely navigate around in the BIM/4D simulation on a scale 1:1 and take distance measurements and query objects for information in properties from IFC. 


\subsection{Examples from using the VPP-system and VR for constructability analysis.}

This section highlights some of the findings related to constructability analysis, both in VPP and VR, during the research project. The examples present the importance of introducing a user-friendly collaborative planning and scheduling tool that supports subcontractors' involvement and specific data from construction workers in this process. The first example transpired on two occasions during the research project: during a VPP collaborative planning and scheduling workshop, and in a VR sequencing planning meeting on the construction site. The participants identified a sequencing planning problem between electricians' cable trays and drywall installation and painting on both these occasions.

First case:
“...The Electrician needs to get the cable trays in place, but then [the painter] needs to paint before. Ok, but the painter is scheduled to come in two weeks from now... then we show that the whole sequence is delayed. Such a system as this makes this visible" (Site manager during VPP-workshop)

Second case:
"... as you can see here. We cannot reach and use the screwdriver during install of the gypsum board... We have to install the structure part of the drywall first and install the gypsum board first, before the Electrician's cable trays are installed... (during the discussion in multi-user VR sequencing planning on construction site)

Fig. 15 shows how the drywalling activities' supervisor in the second case above illustrate the use of VR illustrates the sequencing problem using the VR controls to show that it is hard to get a screwdriver in between the cable tray and the wall.

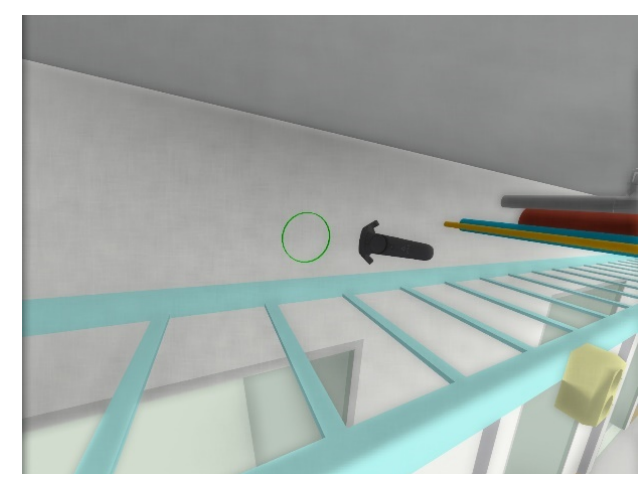

FIG. 15: The supervisor of the drywalling crew using the VR-controller to mimic a screwdriver to illustrate the available space.

The third case is a 4D simulation and sequencing planning workshop conducted on the rebar work and steel stabilisation structure in a high-rise building. The workshop was conducted with the support of BIMXplorer in VR with an HMD, see Fig. 16. The rebar construction workers found constructability issues on clashes. They explained that the VR interface was a user-friendly interface, and that they better understood the rebar work sequencing and got a better perception of the space and details. This was enabled since they could also explore, measure, select and get information about the steel structures' components and rebars such as types, weight, length. During the sequencing planning workshop, it was recognised that VR gave a better understanding of other disciplines and the sequencing of the coming weeks. The workers highlighted that:

\section{"Everyone sees the same thing with VR".}



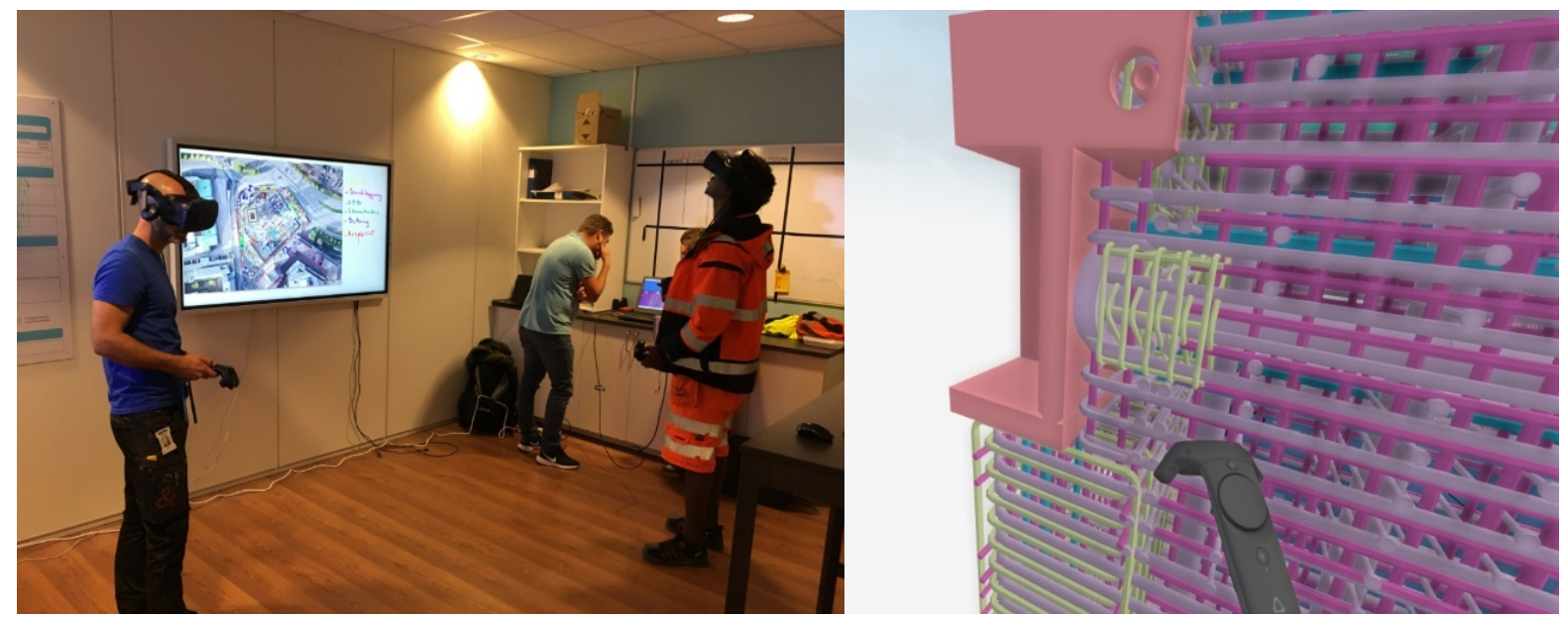

FIG. 16: During one of the construction site preparation and 4D visualisation using multi-user VR it become clear for the construction and site manager that "...this one weighs over two tons..."

Furthermore, with the support of multiple users in VR, the different construction workers could interactively be in the same virtual instance of the worksite and discuss and solve the sequencing planning together. An example occurred during the sequencing of some steel structure and rebar work. One of the construction workers recognised in VR that one of the steel stabilisation components was unusually large, and through the extraction of BIM information in VR, it was realised that the weight was about $2000 \mathrm{~kg}$. See the citation and Fig 16 from one of the workers below.

“...this one weighs over two tons. How should we install it? Will the wires from the crane be blocked from above? Or what sequence should we assembly the rebars and walls? ..."

Thus, these cases exemplify how the project's understanding and planning and scheduling are enhanced both in the VPP system and VR in HMDs.

\section{DISCUSSION AND CONCLUSIONS}

This paper has initially compared a collaborative production planning (CPP) method and traditional 4D scheduling using process modelling. The CPP method are instantiated as the VPP-system with VR to support collaborative 4D planning and scheduling. The result and analyses of the process modelling show that the traditional 4D method relies on existing schedules produced by specialist planners in cooperation with BIM coordinators and often has limited support for collaboration. There is a need for a user-friendly interface since traditional 4D systems are often too complex, and specialist competence is needed to produce the $4 \mathrm{D}$ visualisation, as seen in the traditional 4D process analysis in Fig 4. Furthermore, traditionally the 4D model have mainly been used for reviewing the existing construction schedule in 3D. These reviews have shown to increase the users understanding of the schedule and have been used as a passive visual communication tool of the construction schedule. However, the traditional 4D modelling process is limited when it comes to collaboration during the schedule creation phase. Due to this, Büchmann-Slorup (2010), argues that the full potential of 4D implementation is not achieved and claims that the engagement of subcontractors, suppliers and manufacturers are essential as the schedule is not based on actual knowledge from construction site workers. Similar engagement arguments can be found in research into VR in the design phase (Roupé et al., 2016; Zaker and Coloma, 2018).

In this context, we argue that the presented CPP method and its instantiation in the VPP-system instead of traditional 4D scheduling, can support and enable co-creation in a more user-friendly interface. Evaluations show that the use of VR and HMDs has been found to facilitate a better understanding of the project and the schedule review process. Thus, it is possible to increase worker- and subcontractor- engagement and let these plan, schedule, and review in 4D. The outcome from this process removes the guesswork from the project planner's work and improves empowerment and buy-in into the schedule at all levels, which has been a highlighted issue then it comes to scheduling (Dvir et al., 2003; Faniran et al., 1994; Laufer, 1992; Viklund Tallgren et al., 2015). The process modelling also reveals how the traditional 4D scheduling process can go from being a passive process of linking 
the prepared schedule and 3D model to become an active and socially creative 4D modelling process as seen in the VPP-system. The move from passive participants to active social creativity is further enhanced with VR seen in Johansson \& Roupé (2021). This social creativity is achieved by drawing on the collaborative possibilities enabled by the VPP-system and BIMXplorer. Thus, this mitigates the problems of additional effort for 4D identified argument presented by Tulke \& Hanff (2007) and Campagna-Wilson \& Boton (2020). In this context, the $4 \mathrm{D}$ modelling process could become an active and collaborative process, where worker and subcontractor engage and update the schedule, work sequencing and 4D during the construction.

The use of multiple representations and visualisations gives the participants the possibility to understand different points of view and different subtasks of the project and further enhance the project understanding. Since "everyone sees the same thing" with VR in contrast to drawings, VR is predicted to ease communication between different parties. VR has been found to reduce the risk of misinterpretations, according to Johansson \& Roupé (2019). Furthermore, with the possibility to also support 4D simulation in immersive VR, the construction workers and subcontractors are enabled to "step into" a 4D schedule and experience and review the scheduled sequences on a 1:1 scale, giving a much better understanding of the project and the process. Using the VPP-system and VR to support this collaborative process, it is possible to provide opportunities and resources for activities embedded in a social, creative process in which all stakeholders can actively contribute rather than have passive receiving roles. The participants create awareness of each other's work, and the VPP-system supplies mechanisms to help draw out the tacit knowledge during negotiation and communication about planning, scheduling, and conducting the project, which VR further enhances. As shown in this paper and earlier research, VR supports better sequence planning and constructability analysis. Also, as the $4 \mathrm{D}$ simulation in immersive VR is seamlessly integrated with the VPP-system, it is possible to make changes in the 4D schedule in the web-based scheduling interface and have the changes instantly updated in VR. As the 4D is not static, it promotes social co-creation in different spaces and can help better understand different points of view and the connection of different subtasks between various subcontractors. This use of VR helps the construction workers find sequencing planning problems between the different subcontractors and construction disciplines. Thus, integrating the CPP method into the VPP-system and BIMXplorer supports a better interactive design and review of the 4D schedule and the construction.

Furthermore, recent years has seen much focus from software companies on supporting BIM and construction project information-oriented databases on construction site such as Autodesk Forge and Autodesk BIM 360. Furthermore, it has been recognized in Sweden that the construction industry is now focusing on a more "production oriented" model-based approach, where 3D geometry and added information have been the focus and where drawing-less construction sites has started to appear. This type of approach and concept, focusing totally on BIM as the information placeholder and carrier is called "TotalBIM". The TotalBIM concept offers new possibilities regarding the integration of the VPP-method. Essentially, as the model becomes more and more production oriented, both in terms of geometry and information, it becomes more suitable for the VPP-method. With VPP already being cloud-based and object-oriented as far as data storage goes, it is suitable for integration or replacement - with other cloud-based model repositories, such as BIM360. This, in turn, allows for information generated during the VPP workshop, such as time and schedule data, to be feedback into the (single) model repository as object-oriented metadata.

\section{FUTURE WORK}

In the future, it would be interesting to explore and evaluate if VR also could be valuable as an interactive interface during the actual VPP planning process. For example, the Individual planning subprocess, described in Fig. 5, could be performed in VR. During this subprocess, the user selects and groups BIM components into defining activities or tasks needed to complete a work package during that process. By seamlessly integrating the same tools and processes as the VPP-system supports today, but in VR, it would be possible to explore and work with the planning and scheduling in different virtual spaces in multi-user mode. Thus, the possibility of supporting multiple representations and visualisations gives the participants new ways to understand different subtasks.

Furthermore, the Collaborative scheduling subprocess, described in Fig. 6, could also be conducted in different physical and digital spaces, such as immersive VR co-located and remotely. An example could be the projector displaying the environment along with the client views. However, space could also be different physical locations, for example, remotely. In this context, the VR interface could be a more natural user interface to better understand, create activities and schedule sequences in a 1:1 scale. Thus, the existing original collaborative planning and 
scheduling method can be enhanced during the 4D modelling process. Here, the potential use of the multiple-user mode in VR enables user-avatars to collaborate in VR space interactively. The VR interface could also help review and find worksite safety problems more intuitively.

\section{ACKNOWLEDGEMENTS}

This paper is a substantially extended and enhanced version of the paper presented at the 20th International Conference on Construction Applications of Virtual Reality (CONVR 2020). We would like to acknowledge the editorial contributions of Professor Nashwan Dawood and Dr. Farzad Rahimian of Teesside University in the publication of this paper. This work is part of the Digital Twin Cities Centre supported by Sweden's Innovation Agency Vinnova under Grant No. 2019-00041 and funded by SBUF (Development Fund of the Swedish Construction Industry).

\section{REFERENCES}

Alizadehsalehi S and Yitmen I (2021) Digital twin-based progress monitoring management model through reality capture to extended reality technologies (DRX). Smart and Sustainable Built Environment. DOI: 10.1108/SASBE-01-2021-0016.

Aram S, Eastman CM, Sacks R, et al. (2010) Introducing a New Methodology to Develop the Information Delivery Manual for AEC Projects. Exchange Organizational Behavior Teaching Journal (Nibs 2008): 16-18.

Azhar S (2017) Role of Visualization Technologies in Safety Planning and Management at Construction Jobsites. Procedia Engineering 171: 215-226. DOI: 10.1016/j.proeng.2017.01.329.

Baldwin A and Bordoli D (2014) Handbook for Construction Planning and Scheduling. John Wiley \& Sons.

Borrmann A, König M, Koch C, et al. (2018) Building Information Modeling: Why? What? How? Building Information Modeling: Technology Foundations and Industry Practice. DOI: 10.1007/978-3-319-9286231 .

Boton C (2018) Supporting constructability analysis meetings with Immersive Virtual Reality-based collaborative BIM 4D simulation. Automation in Construction 96(May). Elsevier: 1-15. DOI: 10.1016/j.autcon.2018.08.020.

Boton C, Kubicki S and Halin G (2013) Designing adapted visualization for collaborative 4D applications. Automation in Construction 36(0): 152-167. DOI: https://doi.org/10.1016/j.autcon.2013.09.003.

Buchmann-Slorup R, Andersson N, Büchmann-Slorup R, et al. (2010) BIM-based scheduling of Construction-A comparative analysis of prevailing and BIM-based scheduling processes. In: Proc., 27 the Int. Conf. of the $C I B$ W78, 2010, pp. 113-123. Available at: http://itc.scix.net/data/works/att/w78-2010-113.pdf.

Campagna-Wilson J and Boton C (2020) Challenges Related to 4D BIM Simulation in the Construction Industry. Lecture Notes in Computer Science (including subseries Lecture Notes in Artificial Intelligence and Lecture Notes in Bioinformatics). Springer International Publishing. DOI: 10.1007/978-3-030-60816-3_30.

Chavada R, Dawood N and Kassem M (2012) Construction workspace management: The development and application of a novel $\mathrm{nD}$ planning approach and tool. Journal of Information Technology in Construction 17: 213-236. Available at: http://www.scopus.com/inward/record.url?eid=2-s2.084867883768\&partnerID=40\&md5=2853b269269c1ec5f32dd685d7923156.

Chou HY and Yang J Bin (2017) Preliminary Evaluation of BIM-based Approaches for Schedule Delay Analysis. IOP Conference Series: Materials Science and Engineering 245(6). DOI: 10.1088/1757$899 \mathrm{X} / 245 / 6 / 062048$.

Christiansen F (2012) The Planning Process at a Construction Site. Chalmers University of Technology.

Chrzanowski EN and Johnston DW (1986) Application of linear scheduling. Journal of Construction Engineering and Management 112(4): 476-491. DOI: 10.1061/(ASCE)0733-9364(1986)112:4(476).

Crowther J and Ajayi SO (2019) Impacts of 4D BIM on construction project performance. International Journal of Construction Management 0(0). Taylor \& Francis: 1-14. DOI: 10.1080/15623599.2019.1580832. 
Dadashi Haji M, Taghaddos H, Sebt MH, et al. (2021) The effects of bim maturity level on the 4d simulation performance: An empirical study. International Journal of Engineering Transactions C: Aspects 34(3): 606614. DOI: $10.5829 /$ ije.2021.34.03c.03.

Dvir D, Raz T and Shenhar AJ (2003) An empirical analysis of the relationship between project planning and project success. International Journal of Project Management 21(2): 89-95.

Eastman CM, Teicholz P, Sacks R, et al. (2011) BIM Handbook: A Guide to Building Information Modeling for Owners, Managers, Designers, Engineers and Contractors. John Wiley \& Sons.

Faniran OO, Oluwoye JO and Lenard D (1994) Effective construction planning. Construction management and economics 12(6): 485-499.

Formoso CT, dos Santos A and Powell JA (2002) An exploratory study on the applicability of process transparency in construction sites. Journal of Construction Research 3(01): 35-54.

Friblick F and Nordlund T (2013) Framgångsrik planering i byggprojekt.

Getuli V, Capone P, Bruttini A, et al. (2020) BIM-based immersive Virtual Reality for construction workspace planning: A safety-oriented approach. Automation in Construction 114(February). Elsevier: 103160. DOI: 10.1016/j.autcon.2020.103160.

Goulding JS, Rahimian FP and Wang X (2014) Virtual reality-based cloud BIM platform for integrated AEC projects. Journal of Information Technology in Construction 19(August 2013): 308-325.

Hafsia M, Monacelli E and Martin H (2018) Virtual reality simulator for construction workers. ACM International Conference Proceeding Series. DOI: 10.1145/3234253.3234298.

Heesom D and Mahdjoubi L (2004) Trends of 4D CAD applications for construction planning. Construction Management and Economics 22(22): 171-182. DOI: 10.1080/0144619042000201376.

Hevner A and Chatterjee S (2012) Design Research in Information Systems. Sharda R and Voss S (eds). Springer. DOI: $10.1007 / 978-1-4419-6108-2$.

Hevner AR, March ST, Park J, et al. (2004) Design science in information systems research. MIS quarterly 28(1): $75-105$.

Johansson M (2016) From BIM to VR - The design and development of BIMXplorer. Chalmers University of Technology. Available at: http://www.cmb-chalmers.se/wpcontent/uploads/2015/10/From_BIM_to_VR_Thesis_FINAL_Mikael_Johansson_small.pdf.

Johansson M and Roupé M (2019) BIM and Virtual Reality (VR) at the construction site. In: Proceedings of the 19th International Conference on Construction Applications of Virtual Reality, Bankok, Thailand, 2019.

Johansson M and Roupé M (2021) Kan VR förbättra kundskapsåterföring från produktionen under projekering? SBUF Rapport 13763. Göteborg.

Johansson M, Roupé M and Viklund Tallgren M (2014) From BIM to VR - Integrating immersive visualizations in the current design process. In: Fusion-Proceedings of the 32nd eCAADe Conference-Volume 2 (eCAADe 2014), 2014, pp. 261-269.

Jones EF (2009) Scheduling 101 - the basic of best practices. Paper presented at PMI ${ }^{\circledR}$ Global Congress 2009_ North America, Orlando, FL. Orlando: Project Management Institute, Inc. Available at: https://www.pmi.org/learning/library/schedule-101-basic-best-practices-6701.

Laufer A (1992) A micro view of the project planning process. Construction management and economics 10(1): $31-43$.

Laufer A and Tucker RL (1987) Is construction project planning really doing its job? A critical examination of focus, role and process. Construction management and economics 5(3): 243-266.

Lee SS, Kim KT, Tanoli WA, et al. (2020) Flexible 3D Model Partitioning System for nD-Based BIM Implementation of Alignment-Based Civil Infrastructure. Journal of Management in Engineering 36(1): 04019037. DOI: 10.1061/(asce)me.1943-5479.0000725. 
Mahalingam A, Kashyap R and Mahajan C (2010) An evaluation of the applicability of 4D CAD on construction projects. Automation in Construction 19(2): 148-159. DOI: https://doi.org/10.1016/j.autcon.2009.11.015.

Muhammad AA, Yitmen I, Alizadehsalehi S, et al. (2020) Adoption of Virtual Reality (VR) for Site Layout Optimization of Construction Projects. Teknik Dergi: 9833-9850. DOI: 10.18400/tekderg.423448.

Olivieri H, Seppänen O, Alves TDCL, et al. (2019) Survey Comparing Critical Path Method, Last Planner System, and Location-Based Techniques. Journal of Construction Engineering and Management 145(12). DOI: 10.1061/(ASCE)CO.1943-7862.0001644.

Ouyang C, Dumas M, Van Der Aalst WMP, et al. (2009) From Business Process Models to Process-Oriented Software Systems. ACM Transactions on Software Engineering and Methodology 19(1): 1-37. DOI: $10.1145 / 1555392.1555395$.

Pour Rahimian F, Chavdarova V, Oliver S, et al. (2019) OpenBIM-Tango integrated virtual showroom for offsite manufactured production of self-build housing. Automation in Construction 102(February). Elsevier: 1-16. DOI: 10.1016/j.autcon.2019.02.009.

Pour Rahimian F, Seyedzadeh S, Oliver S, et al. (2020) On-demand monitoring of construction projects through a game-like hybrid application of BIM and machine learning. Automation in Construction 110. DOI: 10.1016/j.autcon.2019.103012.

Roupé M, Viklund Tallgren M, Johansson M, et al. (2014) Virtuellproduktionsplannering med hjälp av BIM och visualisering. SBUF Rapport 12851. Göteborg.

Roupé M, Johansson M, Viklund Tallgren M, et al. (2016) Immersive visualisation of building information models: Usage and future possibilities during design and construction. CAADRIA 2016, 21st International Conference on Computer-Aided Architectural Design Research in Asia - Living Systems and Micro-Utopias: Towards Continuous Designing: 673-682.

Roupé M, Johansson M and Viklund Tallgren M (2017) Virtuell Produktions Modell i Skala 1:1 på Byggarbetsplatsen. SBUF Rapport 13033. Göteborg.

Roupé M, Johansson M, Maftei L, et al. (2019) Seamless Integration of Multi-touch Table and Immersive VR for Collaborative Design. Advances in Informatics and Computing in Civil and Construction Engineering: 263270. DOI: $10.1007 / 978-3-030-00220-632$.

Saluja C (2009) A process mapping procedure for planning building information modeling (BIM) execution on a building construction project. Architectural Engineering.

Sheikhkhoshkar M, Pour Rahimian F, Kaveh MH, et al. (2019) Automated planning of concrete joint layouts with 4D-BIM. Automation in Construction 107(April). Elsevier: 102943. DOI: 10.1016/j.autcon.2019.102943.

Söderberg J (2006) Concordia - försök med integrerad planering. Lund.

Tiferes J and Bisantz AM (2018) The impact of team characteristics and context on team communication: An integrative literature review. Applied Ergonomics 68(November 2017). Elsevier: 146-159. DOI: 10.1016/j.apergo.2017.10.020.

Tulke J and Hanff J (2007) 4D Construction Sequence Planning - New Process and Data Model. Proceedings of CIB-W78 24th International Conference on Information Technology in Construction: 79-84. Available at: http://citeseerx.ist.psu.edu/viewdoc/download?doi=10.1.1.116.4602\&amp;rep=rep1\&amp;type=pdf.

Viklund Tallgren M (2018) Developing a collaborative planning tool for construction - A Building Information Model-enhanced planning and scheduling tool for production. Chalmers University of Technology.

Viklund Tallgren M, Roupé M and Johansson M (2015) An empowered collaborative planning method in a Swedish construction company - A case study. In: 31st Annual ARCOM Conference, Lincoln, UK, 2015, pp. 793-802. Association of Researchers in Construction Management.

Viklund Tallgren M, Roupé M, Johansson M, et al. (2020) BIM tool development enhancing collaborative scheduling for pre-construction. Journal of Information Technology in Construction 25: 374-397. DOI: $10.36680 /$ j.itcon.2020.022. 
Viklund Tallgren M, Roupé M and Johansson M (2020) Collaborative Scheduling With 4D Extended To Virtual Reality. In: Enabling the Development and Implementation of Digital Twins: Proceedings of the 20th International Conference on Construction Applications of Virtual Reality (eds N Dawood, F Pour Rahimian, S Seyedzadeh, et al.), Middlesbourgh, 2020, pp. 73-85. Available at: https://research.tees.ac.uk/files/17140106/CONVR2020_Proceedings.pdf.

Winch GM and Kelsey J (2005) What do construction project planners do? International Journal of Project Management 23(2): 141-149. DOI: https://doi.org/10.1016/j.ijproman.2004.06.002.

Wolfartsberger J (2019) Analyzing the potential of Virtual Reality for engineering design review. Automation in Construction 104(November 2018). Elsevier: 27-37. DOI: 10.1016/j.autcon.2019.03.018.

Zaker R and Coloma E (2018) Virtual reality-integrated workflow in BIM-enabled projects collaboration and design review: a case study. Visualization in Engineering 6(1). Visualization in Engineering. DOI: 10.1186/s40327-018-0065-6. 